\title{
The Impact of Flipped Learning on Achievement and Attitudes In Higher Education
}

\author{
Azizah Saad ALRowais \\ College of Education, Salman bin Abdul-Aziz University \\ Saudi Arabia
}

\begin{abstract}
Although the flipped learning is considered to be one of the main forms of blended learning, no studies were conducted at Saudi universities on the effectiveness of this form of learning. The main objective of the present study was to investigate the effectiveness of flipped learning on the students' achievement and attitudes towards studying courses at Salman bin Abdul-Aziz University. The present study employed the descriptive method to determine the principles of flipped learning to prepare the flipped classroom courses, and the quasiexperimental method to measure the effectiveness of the independent variable (flipped learning) and its impact on the dependent variables (achievement and attitude). Sixty four students who represent the sixth level of the college of education were selected randomly. Achievement test and attitudes scale were used to gather the data. The study showed that there was positive effects of both the students' achievement and their attitudes towards studying courses.
\end{abstract}

\section{Introduction}

Flipped learning has become an increasingly popular instructional strategy and has gained increasing attention among educators and practitioners worldwide as a consequence of the widely accepted trend to shift the focus from teacher to learner in instruction. There is general agreement in the literature that learner achievement grows, in part, out of the individual learner's acceptance of responsibility for his or her own learning. Learners must take at least some of the initiative to give shape and direction to the learning process and must share in monitoring progress and evaluating the extent to which learning targets are achieved.

A flipped (or inverted) classroom is a specific type of blended learning to move lectures outside the classroom. It is a form of of learning in which students learn new content online by watching video lectures, usually at home, and what used to be homework (assigned problems) is now done in class with teachers offering more personalized guidance and interaction with students, instead of lecturing. This is also known as backwards classroom [1].

In terms of Bloom's revised taxonomy, this means that students are doing the lower levels of cognitive work (gaining knowledge and comprehension) outside of class, and focusing on the higher forms of cognitive work (application, analysis, synthesis, and/or evaluation) in class, where they have the support of their peers and instructor. This model contrasts from the traditional model in which "first exposure" occurs via lecture in class, with students assimilating knowledge through homework; thus the term "flipped classroom" [2].

To counter common misconceptions and bring clarity to discussions about "Flipped Learning", the governing board and key leaders of the Flipped Learning Network (2014) announced a formal definition of the term: "Flipped Learning is a pedagogical approach in which direct instruction moves from the group learning space to the individual learning space, and the resulting group space is transformed into a dynamic, interactive learning environment where the educator guides students as they apply concepts and engage creatively in the subject matter" [3].

By providing an opportunity for students to use their new factual knowledge while they have access to immediate feedback from peers and the instructor, the flipped classroom helps students learn to correct misconceptions and organize their new knowledge such that it is more accessible for future use. Furthermore, the immediate feedback that occurs in the flipped classroom also helps students recognize and think about their own growing understanding.

Researchers concluded that while a promising strategy, flipped learning does not work in all contexts. They stressed that more research is needed to determine how and when flipping works to improve student learning.

\section{Theoretical Basis}

The flipped classroom approach is rooted in socio-constructivist theories of education and active learning, but also includes and values educational media for delivery. Vygotsky [4] posited the theory of The Zone of Proximal Development (ZPD) which is a theory of how students' learning is dependent on their prior knowledge in the area and how they fit new knowledge into their already existing mental schema. The theory of ZPD includes the assertion that students can reach some understanding of a topic 
area on their own through independent learning, but they need the assistance of a capable educator to reach their full potential specifically through educator and peer modeling, scaffolding, and specific feedback [4].

The theory of ZPD informs the flipped class because instructional media can be assigned to introduce new knowledge, but without the guidance and feedback from a qualified educator, a student may not be able to make sense of the deeper meaning of the content. Collaborative learning and peer instruction during class time adds new knowledge and understanding to their prior knowledge in a topic area.

How People Learn, the seminal work from John Bransford, Ann Brown, and Rodney Cocking, reports three key findings about the science of learning, two of which help explain the success of the flipped classroom. Bransford and colleagues assert that [5]:

"To develop competence in an area of inquiry, students must: a) have a deep foundation of factual knowledge, b) understand facts and ideas in the context of a conceptual framework, and c) organize knowledge in ways that facilitate retrieval and application" [5].

The flipped classroom helps students learn to correct misconceptions and organize their new knowledge by providing an opportunity for students to use their new factual knowledge while they have access to immediate feedback from peers and the instructor. Figure 1 briefly describes the difference between traditional and flipped learning.

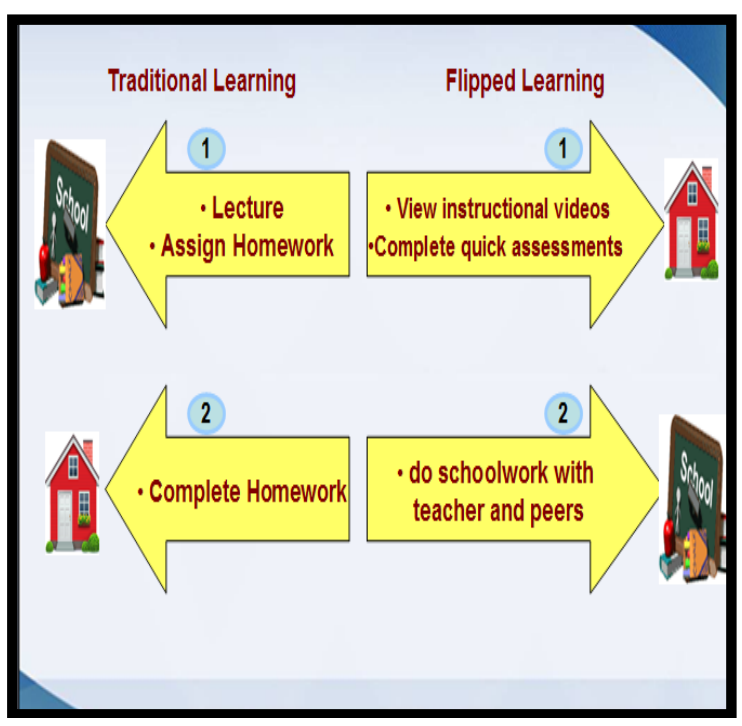

Figure 1. The difference between traditional and flipped learning
The idea of a "flipped classroom" is most often attributed to two high school science teachers, Jonathan Bergmann and Aaron Sams, who used online videos to provide instruction to their students so as to free up more time for lab work; and to Salman Khan, whose Khan Academy videos teaching people math techniques were so popular that teachers began assigning them to students to watch outside of school time. In a recent interview, founders of the flipped classroom movement, Jon Bergmann and Aaron Sams, explained that a flipped classroom shifts the emphasis of teaching from the instructor to the learner [6].

Flipped learning has attracted research and practice-based attention for its potential to incorporate digital technologies in a new pedagogical method that is better aligned with current collaborative constructivist educational practice, also known as 'the flipped approach' or 'the inverted classroom'.

The essence of the flipped method is that content is delivered before class time, and lectures themselves become forums for discussion, integration, and application of that content. The predelivered content may take several formats, most typically a series of short videos recorded using simple video-capture software and uploaded to the internet. These videos may be supplemented by Web 2.0 resources or platforms such as wikis, blogs, discussion forums, social media sharing, and social networking sites, which support active and social learning by acting as venues for collaborating, constructing and sharing information in support of active and social learning [7]. In class time, the lecturer acts as facilitator, guiding students in discussion either individually or in groups.

\section{Flipped Learning in Higher Education}

In higher education, teaching faculty has a history of moving the course content to outside the class. Think of the science class where students read about the theory and then use lab time to practice the techniques, or the English course in which the professor gave instant feedback on writing exercises during the class time. It is not surprising to see that a growing number of teaching faculty are leveraging new technologies and are embracing the flipped model.

A growing number of higher education individual faculty have begun using the flipped model in their courses. At Algonquin College, a video production class has been using this model to explain the workings of editing software, a procedure that is notoriously difficult to explain in a standard lecture. Short tutorial video lectures let students move at their own pace, rewind to review portions, and skip through sections they already understand, meaning students come to class able to use the software and 
prepared to do creative projects with their peers. A particularly successful example of a blended and flipped class in accounting at Penn State accommodates 1,300 students. In-class time is used for open discussion, a featured guest speaker, or hands-on problem solving where instructor support is supplemented by student assistants. At Harvard University, one physics professor not only employs the flipped model but has also developed a correlative site, Learning Catalytics, which provides instructors with free interactive software enabling students to discuss, apply, and get feedback from what they hear in lecture [8].

The governing board and key leaders of the Flipped Learning Network (FLN) distinguish between a Flipped Classroom and Flipped Learning. Flipping a class can, but does not necessarily, lead to Flipped Learning.

To engage in Flipped Learning, teachers must incorporate the following four pillars into their practice. Figure 2 briefly describes the four pillars of flipping learning [3].

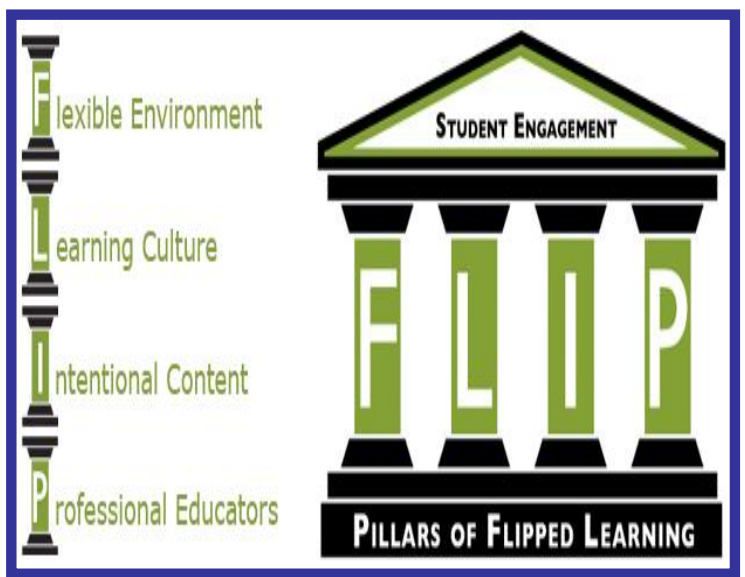

Figure 2. The four pillars of flipping learning (FLN, 2014)

- First pillar: Flipped learning requires flexible environments. Flipped classrooms allow for a variety of learning modes; educators often physically rearrange their learning space to accommodate the lesson or unit, which might involve group work, independent study, research, performance, and evaluation. They create Flexible Environments in which students choose when and where they learn. Flipped educators accept that the in-class time will be somewhat chaotic and noisy, as compared with the quiet typical of a well-behaved class during a lecture. Furthermore, educators who flip their classes are flexible in their expectations of student timelines for learning and how students are assessed. Educators build appropriate assessments systems that objectively measure understanding in a way that is meaningful for students and the teacher.
- Second pillar: Flipped learning requires a shift in learning culture. In the traditional teachercentered model, the teacher is the main source of information, the teacher is the "sage on the stage" (King, 1993), i.e. the sole content expert who provides information to students, generally via direct instruction lecture. In the Flipped Learning model, there is a deliberate shift from a teachercentered classroom to a student-centered approach, where in-class time is meant for exploring topics in greater depth and creating richer learning opportunities. Students move from being the product of teaching to the center of learning, where they are actively involved in knowledge formation through opportunities to participate in and evaluate their learning in a manner that is personally meaningful. Students can theoretically pace their learning by reviewing content outside the group learning space, and teachers can maximize the use of face-to-face classroom interactions to check for and ensure student understanding and synthesis of the material. Flipped educators help students explore topics in greater depth using student-centered pedagogies aimed at their readiness level or zone of proximal development, where they are challenged but not so much so that they are demoralized.

- Third pillar: Flipped learning requires intentional content. Flipped educators evaluate what content they need to teach directly, since lectures are an effective tool for teaching particular skills and concepts, and what materials students should be allowed to explore first on their own outside of the group learning space. They continually think about how they can use the Flipped Learning model to help students gain conceptual understanding, as well as procedural fluency. Educators use Intentional Content to maximize classroom time in order to adopt various methods of instruction such as active learning strategies, peer instruction, problem-based learning, or mastery or Socratic methods, depending on grade level and subject matter. If they continue to teach using a teacher-centered approach, nothing will be gained.

- Four pillar: Flipped learning requires professional educators. Some critics of Flipped Learning have suggested that the instructional videos employed in the model will eventually replace educators. That is misguided. In the Flipped Learning model, skilled, Professional Educators are more important than ever, and often more demanding, than in a traditional one. They must determine when and how to shift direct instruction from the group to the individual learning space, and how to maximize the face-to-face time between teachers and students. During class time, educators continually observe their students, 
provide them with feedback relevant in the moment, and continuously assess their work. Professional Educators are reflective in their practice, connect with each other to improve their trade, accept constructive criticism, and tolerate controlled classroom chaos. While Professional Educators remain very important, they take on less visibly prominent roles in the flipped classroom.

The benefits to this inverted model are many. Students pace and direct their own learning, exploring pre-delivered materials in their own time, repeatedly if they wish. The approach demands their active engagement in the learning process. The lecture room becomes an interactive space where students collaboratively construct their own knowledge in ways that is meaningful to them, receiving personalized guidance and becoming a part of a community of inquiry [9].

Studies have indicated support for the appropriate use of flipped learning strategies. The goal of such studies is to allow students to choose the learning methodology that best fit their individual, so students can receive multiple methods of learning major concepts outside the classroom. Students could read a textbook, view a PowerPoint presentation, or watch a video lecture online [10], [11], [12].

Some studies also have indicated that open-ended problem solving experiences can be learning style conducted within the classroom environment to allow for more engaged pedagogies [13].

Findings of a number of studies support the potential of flipped learning in education and instruction [14] [15] [16]. But these studies were conducted in non-Saudi surroundings, a case further justifying the need for the study being implemented in the Saudi community.

\section{Statement of the problem}

The problem of the present study lies on the fact that high education students in Saudi Arabia face difficulties in learning, as a result of using traditional teaching methods unsuitable to their age stage such as Lecture-based instruction that allows students to take a passive learning role. Students who are motivated and engaged will do well, but others will fail simply because they are not force to think critically and engage in the content. Furthermore, there is continuously a need for improvement and innovation of teaching methods and learning types. The current study is linked to the developmental dimension especially embodied in the teaching methods, related to the students' requirements and abilities, the requirements for innovation, going out of the borders of traditional methods, concerning the methods relevant to all implications of psychological and mental characteristics which should be observed.
In the light of the above, the researcher felt the need for the application of this study as a response to the calls of education scholars for the employment of various educational methods and techniques, concerning the characteristics of age stage and students' requirements to develop self-autonomy. This study -according to the researcher's best knowledge- is highly probably one of the pioneering studies in the KSA aiming at application of flipped learning and examine its effectiveness on Saudi students' achievement and attitude towards learning university courses. The problem of the study was identified in the following main question: (What is the effectiveness of flipped learning on the students' achievement and attitudes towards studying courses at Salman bin Abdul-Aziz University?".

\subsection{Study Hypotheses}

To answer the study question, the following hypotheses were tested:

1. There are no statistically significant differences at (0.05 level) between the mean scores of the experimental group and the control group in the post application of the achievement tests of university courses.

2. There are no statistically significant differences at (0.05 level) between the pre and post measurement of the experimental group attitudes towards studying university courses.

\section{Study objective}

The study aimed to investigate the effectiveness of flipped learning on the students' achievement and attitudes towards studying courses at Salman bin Abdul-Aziz University.

\subsection{Significance of the study}

The importance of the study lies in the following considerations:

- It is a response to the calls of education scholars for the employment of various educational methods and theories, concerning the characteristics of age stage and students' requirements.

- The findings of this study may support the achievement of the objectives of teaching \& instruction towards the development of learning, and the actual practice of university courses.

- This study -according to the researcher's best knowledge- is highly probably one of the pioneering studies in the KSA aiming at application of flipped learning to examine its effectiveness on Saudi students' achievement and attitudes. 
- It may draw the attention of the course designers to include more and more of flipped learning activities in high education programs in order to provide different fields of practice, concerning the students' requirements.

- The findings of this study may hopefully help researchers to conduct further similar studies in this field in order to find the effective teaching methods and theories for the development learning or the development of communication skills at high education.

\section{Research Method}

In order to test the hypotheses, the present study employed the descriptive method to determine the principles of flipped learning to prepare the flipped classroom courses, and the quasi-experimental method to measure the effectiveness of the independent variable (flipped learning) and its impact on the dependent variables (achievement and attitude). Sixty four students who represent the sixth level of the college of education were selected randomly. Achievement test and attitudes scale were used to gather the data.

\subsection{Study Participants}

The study sample was composed of Sixty four students who represent the sixth level of the college of education at Salman bin Abdul-Aziz University for the second term of the year 2013-2014. Two classes were randomly selected from one of the departments of the college of education, and randomly assigned to the experimental and control groups of the study.

The variables assumed relevant to the present study were controlled as follows: All the students were females of the same age (20-21 years old), both groups were taught by the researcher, students in the two groups were at the same level of proficiency as measured by the pre-tests.

\subsection{Study Instruments}

The study instruments included the achievement tests of the courses that were pre-post-administered to measure the students' achievement of the experimental and control groups, and the scale of students' attitudes towards learning and studying courses which was pre-post-administered to the students of the experimental group.

The achievement tests were designed by the researcher and each of them included 50 multiplechoice items to measure the students' achievement. Each question had one correct answer and three 'distracters'. The tests have been based on the table of specification which were organized for 3 chapters of the courses. The scale of students' attitudes towards learning and studying courses was designed by the researcher and included 30 items.

To determine the validity of the instruments, they were submitted to ten specialists in Methodology and Psychology. In light of their comments and recommendations, the needed modifications were made. The researcher tried out the instruments by administering them on a sample of 10 university students (other than the sample subjects). This piloting aimed to determine the instruments reliability and timing for application.

The reliability coefficient of the tests were $(0.80$ $0.85)$, which proved to be statistically reliable. The reliability coefficient of the attitude scale was (0.90) which proved to be statistically reliable.

\subsection{Study Procedures}

The study procedures included the preadministration of the study instruments, the treatment and the post-administration of the instruments.

\subsubsection{The pre-administration of the instruments:}

The researcher pre-administered the two achievement tests to measure the Sixth level students' achievement of the experimental and control groups and identify their level in the two courses: (Teaching Methods \&Communication Skills) before the experiment. Also she administered the scale of students' attitudes towards learning and studying courses which was pre-administered to the students of the experimental group before the introduction of the treatment. The pre-administration of the instruments was conducted at the beginning of January 2014. It was administered to sixty four students at Salman University, before they were exposed to the treatment. Table (1) shows the results of the independent samples t- test for the differences between two groups on the pre-administration of achievement test of the course "Teaching Methods":

Table 1. Independent Samples T-test

\begin{tabular}{|c|c|c|c|c|}
\hline Group & No. & Mean & $\begin{array}{c}\text { T- } \\
\text { value }\end{array}$ & $\begin{array}{c}\text { p- } \\
\text { value }\end{array}$ \\
\cline { 1 - 3 } Control & 32 & 10.15 & -1.62 & \multirow{2}{*}{0.11} \\
\cline { 1 - 3 } Experimental & 32 & 11.13 & & \\
\hline
\end{tabular}

Table 2 shows the results of the independent samples t-test for the differences between two groups on the pre-administration of achievement test of the course "Communication Skills": 
Table 2. Independent Samples T-test

\begin{tabular}{|c|c|c|c|c|}
\hline Group & No. & Mean & $\begin{array}{c}\text { T- } \\
\text { value }\end{array}$ & $\begin{array}{c}\text { p- } \\
\text { value }\end{array}$ \\
\hline Control & 32 & 15.92 & \multirow{2}{*}{-1.36} & 0.17 \\
\cline { 1 - 3 } Experimental & 32 & 18.00 & & \\
\hline
\end{tabular}

\subsubsection{The Treatment}

The treatment lasted 12 weeks to investigate the effectiveness of flipped learning on the students' achievement and attitudes towards learning courses at Salman bin Abdul-Aziz University. The researcher chose the content from the two courses: (Teaching Methods \&Communication Skills) and lessons plans were developed for the courses based on the applications of flipped learning model. The materials the researcher used in the treatment were textbooks, video lectures online, PowerPoint presentations, and course management systems. The researcher was involved in teaching the two groups: the experimental group (taught through the flipped classroom applications) and the control group (taught through the traditional method). The subjects of the experimental group were taught by the researcher through the applications of the flipped classroom. Students received instruction at home from videos and PowerPoint presentations on the website, and in class, worked in small learning communities to problem-solve.

The following steps were used for the experimental group through the treatment:

- Before the class, instructor prepares learning opportunities through creating videos PowerPoint presentations and using course management systems. Students gain necessary knowledge before class through reading textbooks, watching video lectures online and PowerPoint presentations at home. Students guided through learning module that asks and collects questions.

- At the Beginning of Class, students have specific questions in mind to guide their learning, and Instructor can anticipate where students need the most help.

- During Class, students practice performing the skills they are expected to learn. Instructor guides the process with feedback and minilectures. During class, students are broken into small groups and engaged in active learning assignments such as problem solving, presentations and discussions.

- After Class, students continue applying their knowledge skills after clarification and feedback. Instructor posts any additional explanations and resources as necessary and grades higher quality work. Students are equipped to seek help where they know they need it.

\subsubsection{The post-administration of the instruments:}

After implementing the treatment, its effectiveness was evaluated by post-administration of the instruments. The content of the preadministration and the post-administration was the same. The achievement tests of the courses were post-administered to measure the students' achievement of the experimental and control groups, and the scale of students' attitudes towards learning courses was post-administered to the students of the experimental group. The statistical procedures were applied on the data obtained using the means and ttests. Table 3 shows the results of the independent samples t-test for the differences between two groups on the post-administration of achievement test of the course "Teaching Methods":

Table 3. Independent Samples T-test

\begin{tabular}{|c|c|c|c|c|}
\hline Group & No. & Mean & $\begin{array}{c}\text { T- } \\
\text { value }\end{array}$ & $\begin{array}{c}\text { p- } \\
\text { value }\end{array}$ \\
\hline Control & 32 & 10.65 & -10.36 & \multirow{2}{*}{0.00} \\
\hline Experimental & 32 & 18.68 & & \\
\hline
\end{tabular}

The results of the independent samples t- test for the differences between two groups on the postadministration of achievement test of the course " Teaching Methods" revealed that there were significant differences at 0.05 level between the students mean scores on the post-application of the test and these differences were in favor of the EG. So the research hypothesis was rejected because there was a marked improvement in the EG performance on the post-administration of the test. This improvement indicated the effectiveness of the flipped learning in improving the students' achievement in the course.

Table 4 shows the results of the independent samples t-test for the differences between two groups on the post-administration of achievement test of the course "Communication Skills":

Table 4. Independent Samples T-test

\begin{tabular}{|c|c|c|c|c|}
\hline Group & No. & Mean & $\begin{array}{c}\text { T- } \\
\text { value }\end{array}$ & $\begin{array}{c}\text { p- } \\
\text { value }\end{array}$ \\
\cline { 1 - 3 } Control & 32 & 23.37 & & \\
\cline { 1 - 3 } Experimental & 32 & 35.63 & -5.00 & 0.01 \\
\hline
\end{tabular}


The results of the independent samples t- test for the differences between two groups on the postadministration of achievement test of the course "Communication Skills" revealed that there were significant differences at 0.05 level between the students mean scores on the post-application of the test and these differences were in favor of the EG. So the research hypothesis was rejected because there was a marked improvement in the EG performance on the post-administration of the test. This improvement indicated the effectiveness of the flipped learning in improving the students' achievement in the course.

Table 5 shows the results of the paired samples ttest for the differences between the pre-post administrations of scale of students' attitudes towards learning the two courses:

Table 5. Paired Samples T- Test for the differences between the pre-post administrations of the scale of students' attitudes

\begin{tabular}{|c|c|c|c|c|}
\hline $\begin{array}{c}\text { post } \\
\text { administrat } \\
\text { ion }\end{array}$ & No. & Mean & $\begin{array}{c}\text { T- } \\
\text { value }\end{array}$ & $\begin{array}{c}\text { p- } \\
\text { value }\end{array}$ \\
\cline { 1 - 3 } Pre-admin. & 32 & 2.58 & -13.18 & 0.00 \\
\hline Post-admin. & 32 & 3,84 & & \\
\hline
\end{tabular}

The results of the paired samples t-test for the differences between the pre-post administrations of the scale of students' attitudes towards learning the two courses revealed that there were significant differences at 0.05 level between the students mean scores on the pre-post administrations of scale of students' attitudes and these differences were in favor of the post administration. So the research hypothesis was rejected because there was a marked improvement in the EG performance on the postadministration of the attitude scale. This improvement indicated the effectiveness of the flipped learning in improving the students' attitudes towards learning.

\section{Conclusions and Recommendations}

In the light of the findings of this study, the main conclusions were:

1. There are statistically significant differences at (0.05 level) between the mean scores of the experimental group (taught through the flipped learning strategies) and the control group (taught through the usual method) in the post application of the achievement tests in favor of the experimental group.

2. There are statistically significant differences at (0.05 level) between the pre and post measurement of the experimental group attitudes towards learning the university courses in favor of the post measurement.

3. The results of the present study are in line with other researchers such as (Lage and Platt [11]; Marcey and Brint [12]; Chips [10]; Baker [15]; Johnson and Renner [16]).

4. The advantages of flipped learning affected the attitudes of students towards learning. It promotes peer interaction and collaboration skills, encourages higher student's engagement, and makes learning central rather than teaching. This result is in line with [9].

Based on the results of the study, it was recommended that:

1. The faculty members are advised to adopt applications of flipped learning and the use of elearning tools and educational software in teaching because of its effectiveness in the development of the knowledge and skills of students and their attitudes.

2. More attention should be paid to the preparation of workshops and training courses for the training of faculty members at universities on the use of flipped learning strategies and employing e-learning tools and make use of them in the design of courses.

3. The need to provide the necessary capabilities and material support to universities that are required for teaching through management systems and using e-courses, and to provide the necessary equipment to activate its role in improving the level of performance.

4. Course designers are advised to include the four pillars of flipped learning into their practices in order to provide different types of learning styles to shift the focus from teacher to learner in instruction.

\section{References}

[1] Barseghian, Tina, Three Trends That Define the Future of Teaching and Learning. Retrieved from KQED (February 5, 2011).

[2] Anderson, L.W., and D. Krathwohl (Eds.) (2001). A Taxonomy for Learning, Teaching and Assessing: a Revision of Bloom's Taxonomy of Educational Objectives. Longman, New York.

[3] Flipped Learning Network (2014), What is a Flipped Learning? Retrieved from:

http://fln.schoolwires.net/cms/ lib07/VA01923112/Centrici ty/Domain/46/FLIP_handout_FNL_Web.pdf

[4] Vygotsky, L. S. (1978).Mind in society. Cambridge, MA: Harvard University 
[5] Bransford JD, Brown AL, and Cocking RR (2000). How people learn: Brain, mind, experience, and school. Washington, D.C.: National Academy Press.

[6] Noonoo, Stephen (2012). Flipped Learning Founders Set the Record Straight. Retrieved from:http://thejournal.com/articles/2012/06/20/flippedlearning-founders-q-and a.aspx\#TTs2AhWil2zYaZjZ.99

[7] Garrison, D. R., \& Akyol, Z. (2009). Role of instructional technology in the transformation of higher education. Journal of Computing in Higher Education, 21, 19-30. doi: 10.1007/s12528-009-9014-7

[8] EDUCAUSE (2012). THINGS YOU SHOULD KNOW ABOUT FLIPPED CLASSROOMS. http://creativecommons.org/licenses/by-nc-nd/3.0/ Educause.edu/eli

[9] Garrison, D. R., \& Vaughan, H. (2008). Blended learning in higher education: Framework, principles and guidelines. San Francisco: Jossey-Bass

[10] Chips, Joseph. The Effectiveness of Using Online Instructional Videos with Group Problem-Solving to Flip the Calculus Classroom, California State University, Northridge (2012).

Retrieved from http://jchipps.com/docs/thesis.pdf

[11] Lage, M. J., \& Platt, G. (2000). The Internet and the Inverted Classroom. The Journal of Economic Education, 31(1), 11-11.doi:10.1080/002204800009 56756

[12] Marcey, D., \& Brint, M. (2011). Transforming an Undergraduate Introductory Biology Course Through Cinematic Lectures and Inverted Classes: An Assessment of the CLIC Model of the Flipped Classroom. California Lutheran University, Thousand Oaks, CA.

[13] Kellogg, S. (2009). Developing online materials to facilitate an inverted classroom approach (pp. 1-6). IEEE. doi:10.1109/FIE.2009.5350621

[14] Papadapoulos, C. \& Roman, A. S. (2010) Implementing an inverted classroom model in engineering statistics: Initial results. American Society for Engineering Statistics. Proceedings of the 40th ASEE/IEEE Frontiers in Education Conference, Washington, DC, October 2010

[15] Baker, Celia (2012). Flipped classrooms: Turning learning upside down: Trend of "flipping classrooms" helps teachers to personalize education. Deseret News. Retrieved from http:// www.deseretnews.com/ article/765616415/Flipped-classrooms-Turning-learningupside-down. html?pg=all

[16] Johnson, L., \& Renner, J. (2012). Effect of the flipped classroom model on secondary computer applications course: student and teacher perceptions, questions and student achievement (Doctoral Dissertation, University of Louisville). 